\title{
Asthma Prevalence and Severity in Arab American Communities in the Detroit Area, Michigan
}

\author{
Mary Johnson, ${ }^{1}$ Jerome Nriagu, ${ }^{1,4}$ Adnan Hammad, ${ }^{2}$ \\ Kathryn Savoie, ${ }^{2}$ and Hikmet Jamil ${ }^{2,3}$
}

\begin{abstract}
Immigrant populations provide a unique intersection of cultural and environmental risk factors implicated in asthma etiology. This study focuses on asthma prevalence and severity in 600 Arab American households in metro Detroit, the largest immigrant reception zone for Arab Americans in North America. The survey method introduced a number of novel features: (a) a ranking scheme for the key environmental risk factors for asthma was used to derive an aggregated environmental risk index (ERI) for each household, and (b) an aggregate measure of asthma severity based on symptom frequency and intensity. Environmental risk factors and surrogates for socioeconomic status (SES) were found to be stronger predictors of asthma prevalence than asthma severity, while demographic variables such as English fluency and birth in the United States were better predictors of asthma severity than asthma prevalence. These results suggest that SES variables may be more reflective of environmental exposures in communities involved in this study, while English fluency and birth in the United States may be linked to health care access and utilization behavior that can influence the asthma management. We also found a significant relationship between asthma prevalence and degree of acculturation. Asthma prevalence was highest among moderately acculturated immigrants compared with new immigrants and those who were well acculturated, suggesting that among Arab Americans in the Detroit area, risk factors associated with new immigrant status are replaced by "western" risk factors as the population becomes more acculturated.
\end{abstract}

KEY WORDS: asthma; prevalence; severity; indoor air pollution; Arab Americans.

\section{INTRODUCTION}

The Arab American community in southeast Michigan embodies a nexus of factors implicated in the etiology and expression of asthma (1). The community is shaped by multigenerational waves of

\footnotetext{
${ }^{1}$ Department of Environmental Health Sciences, School of Public Health, University of Michigan, Ann Arbor, Michigan.

${ }^{2}$ ACCESS Community Health \& Research Center, 6450 Maple Street, Dearborn Michigan.

${ }^{3}$ Department of Family Medicine, Wayne State University, Detroit, Michigan.

${ }^{4}$ Correspondence should be directed to Jerome Nriagu, Department of Environmental Health Sciences, School of Public Health, University of Michigan, 109 Observatory Street, Ann Arbor, Michigan; e-mail: jnriagu@umich.edu.
}

immigration that began in the late nineteenth century and continue through the present day. Varying degrees of acculturation, education, and English proficiency shape access to employment opportunities and medical assistance. Socioeconomic status (SES) often determines living conditions while SES and cultural background shape lifestyle choices that may play a role in asthma etiology and expression.

Although the relationship between immigration and asthma outcomes remains ambiguous, several studies have suggested that acculturation to Western lifestyle may be an important predictor of asthma outcomes (2). Tobias et al. (3), for instance, found that immigrant populations from Europe, South America, Asia, and Africa who were resident in the United States, Europe, Australia, and New Zealand 
reported greater asthma prevalence compared with the indigenous populations of those countries. Among immigrant populations from developing countries with low asthma incidence, asthma outcomes have been positively correlated with time spent in the developed country (4-6). In contrast, immigrant populations from developed countries with high asthma prevalence residing in other developed countries with high asthma prevalence did not appear to experience higher prevalence, morbidity, and mortality compared with the host population (4). Numerous factors associated with immigration may impact asthma etiology. Cultural beliefs, language barrier, low income, and low socioeconomic status may influence health care access and utilization; while stress and psychological problems associated with translocation and acculturation may increase susceptibility to asthma or exacerbate symptoms among immigrants $(7,8)$. Although immigrant populations may be at higher risk for increased asthma prevalence, morbidity, and mortality, few studies in the United States have considered immigrant populations, and none of the international studies have focused on immigrants from the Middle East. This study focuses on the demographic and environmental risk modifiers for asthma in Arab Americans living in the Detroit Metropolitan area.

The Arab American communities in metro Detroit may be at higher risk for asthma because they (a) embody an urban dwelling, low SES, ethnic minority, and (b) reflect an immigrant population residing in a "westernized" country with high asthma prevalence. Many of the participants in this study live in areas with high volumes of truck traffic and industrial polluters such as the Ford motor plant complex of Dearborn and experience a high burden of environmental exposures to asthma risk factors via substandard housing. One of the goals of this study is to characterize the asthma burden among Arab Americans in metro Detroit, and undertake a preliminary delineation of the environmental risk factors related to asthma in this unique population.

Another goal of this study is to develop a questionnaire instrument to estimate the severity of asthma within a high-risk population, and to ascertain the key risk factors that contribute to asthma severity in contrast with asthma prevalence. Few existing studies have used a similar instrument for severity assessment-most studies focus on frequency of symptoms without reference to symptom intensity or severity. The majority of reported sever- ity measures assess either intensity or frequency. Sarafino et al. $(9,10)$ developed a measure of asthma severity based on the product of frequency and intensity; however, their measure focuses on attack frequency, intensity, and severity. The model presented in this paper uses an aggregate measure of frequency, intensity, and severity for individual symptoms.

\section{METHODS}

The research was conducted in collaboration between Arab Community Center for Economic and Social Services (ACCESS) and the University of Michigan School of Public Health according to the community based participatory research model (11, 12). The guiding principles of this collaboration were as follows: 1) community members have a voice initially and throughout the process including planning design, implementation and evaluation activities, 2) researchers and community members bring their expertise and resources to the project, 3 ) researchers and community members partner to select the most relevant, sound and feasible data collection methods, 4) researchers value the community's history, culture and conditions, and 5) researchers address questions of importance to the community. To ensure protection of safety and human dignity among survey participants, research methods were approved by the University of Michigan Institutional Review Board (IRB) in accordance with federal regulations.

Sample size calculations were performed by PASS 2002 (NCSS Statistical Software, Kaysville, UT). Assuming that asthma prevalence in this population was similar to the $10 \%$ reported prevalence in the state of Michigan, we found that a sample size of 370 was sufficient to achieve a $95 \%$ confidence interval for the prevalence $( \pm 3 \%)$ in this population. We chose a sample size of 600 to allow for an adequate margin of error. All sample size calculations assumed two-sided testing.

\section{Selection of Study Population}

Households were selected from four regions in the Detroit metropolitan area: Dearborn, Hamtramck, Oak Park, and Detroit Seven Mile zone. These areas encompass the predominantly Arab-American immigrant reception pool in Detroit, as well as the heaviest industrial polluters in Wayne County (13). We based the number of participants 
from each area on rough estimates of the proportion of Arab Americans living there.

Participants in Dearborn were selected randomly from a database comprised of Arab-American households using the random number generator function. This area was over-represented in the study due to the large proportion of Arab-Americans living there, and the potential health risks posed by the numerous industrial installations in the community.

A list of residential addresses was obtained from the Oak Park assessor's office, and this database was augmented with a list of individual apartment numbers compiled by the research team. A random number generator function was subsequently used to select household addresses from the database. Following address selection, the Arab American Community Environmental Health Advocates (CEHA) hired for the project went door-to-door to determine whether the households were Arab-American. ArabAmerican households were then asked to participate in the survey.

Prior to the terrorist attacks in New York on September 11th, 2001, advocates approached both Arab and non-Arab American households in the process of recruiting Arab American participants. After the attacks on September 11th, non-Arab Americans reacted with fear and hostility to the Arab-American CEHA, and face-to-face screening became uncomfortable and potentially dangerous. In response to this development, advocates compiled lists of Arab American households using blockby-block survey of predominantly Arab American neighborhoods. Households for the study were then randomly selected from these lists. Although every effort was made to compile thorough address lists, this process may have biased household selection against Arab-American households residing in non-Arab-American neighborhoods in Hamtramck and Seven Mile. The implications of this sampling design will be discussed further.

\section{Household Survey}

Once households eligible for the study were determined, CEHA attempted to contact and secure the consent of an adult member of the household 18 years or older. Advocates initially approached families directly by knocking at the door. The household assessment survey was administered at the initial meeting if the household member was willing and able to participate. If the household member was un- able to do the interview during the initial meeting, the advocates arranged appointments to administer the survey at a more convenient time. All of the interviewers were bilingual, and most of the interviews were conducted in Arabic by the respondent's preference. Participating households received a baseline incentive of $\$ 50$ upon completion of the survey. The survey was carried out between August 2001 and January 2002.

Advocates approached each eligible household at least four times. If they were unable to conduct or schedule an interview within this timeframe, the household was classified as a refusal. These default refusals included households in which no one was home during four separate visits. A few households refused to participate for various reasons. Advocates tried to minimize refusal by carrying appropriate credentials that identified them with ACCESS, a prominent and respected organization in the Detroit Arab-American community, and by making their initial contacts and conducting subsequent assessments in Arabic. The use of two respected Arab American physicians as advocates also helped to reassure some participants. Of the 706 households that were eligible, only $12 \%$ refused to participate directly or by default. Alternate households were not selected because the addresses were over sampled to ensure an adequate number of completed surveys. A total of 618 household surveys were completed: 57\% in Dearborn, $17 \%$ in Hamtramck, $16 \%$ in Seven Mile, and $10 \%$ in Oak Park. Of the 618 completed surveys, 600 were used in the analysis, and 18 were omitted because of gross errors in the completed questionnaire.

\section{Environmental Risk Index}

The survey introduced a novel ranking scheme for assessing environmental risk factors, entitled Environmental Risk Index (ERI), in this paper. The instrument assessed 17 risk factors (Table I) that were used to estimate the environmental risk for each household. The ERI focused on shared household exposures, e.g., risk factors present in living spaces utilized by the entire household such as the kitchen or the family room, or exposures such as heating source or temperature that affect the entire home rather than individual spaces such as a bedroom. The ERI for each household was calculated by scoring the critical risk and protective factors (Table I). Responses indicating protective factors were assigned negative scores. Risk factors were assigned positive 
Table I. Environmental Risk Index (ERI) Determinants

\begin{tabular}{|c|c|c|c|c|}
\hline \multirow[b]{2}{*}{ ERI determinant } & \multicolumn{2}{|c|}{$\begin{array}{c}\text { Possible } \\
\text { score range }\end{array}$} & \multicolumn{2}{|c|}{$\begin{array}{l}\text { Experimental } \\
\text { score range }\end{array}$} \\
\hline & $\begin{array}{l}\text { Min } \\
\text { score }\end{array}$ & $\begin{array}{l}\text { Max } \\
\text { score }\end{array}$ & $\begin{array}{l}\text { Min } \\
\text { score }\end{array}$ & $\begin{array}{l}\text { Max } \\
\text { score }\end{array}$ \\
\hline Landlord repairs & 0 & 2 & 0 & 2 \\
\hline Quality of home & -1 & 1 & -1 & 1 \\
\hline Year home was built & -1 & 1 & -1 & 1 \\
\hline Building materials & 0 & 1 & 0 & 1 \\
\hline Central air conditioning & -1 & 1 & -1 & 1 \\
\hline Basement & -1 & 1 & -1 & 1 \\
\hline Heating source & 0 & 4 & 0 & 4 \\
\hline Type of furnace & 0 & 1 & 1 & 1 \\
\hline Filter on furnace & -2 & 1 & -2 & 1 \\
\hline Indoor temperature & -1 & 1 & -1 & 1 \\
\hline Water leaks & 0 & 3 & 0 & 3 \\
\hline Pets & 0 & 7 & 0 & 4 \\
\hline Cockroaches & 0 & 2 & 0 & 2 \\
\hline Pesticide application & 0 & 2 & 0 & 2 \\
\hline Car/garage & 0 & 6 & 0 & 5 \\
\hline Clothes dryer & 0 & 1 & 0 & 1 \\
\hline Weatherproofing & 0 & 6 & 0 & 6 \\
\hline
\end{tabular}

score values. Factors considered to be neither indicative of risk or protective (13) were assigned a value of zero. Risk and protective factors were assigned relative scores based on the strength of their association with asthma. Risk factors known to have a stronger correlation to asthma were assigned higher positive scores than risk factors with a less demonstrable or weaker association with asthma. Protective factors were similarly assigned relative scores based on their demonstrable correlation with asthma outcomes. Scores for the individual questions were added together to form a summary ERI value for each household.

\section{Measures of Asthma Prevalence, Severity, and Triggers}

Previous studies measured a variety of asthma outcomes ranging from doctor-diagnosed asthma to self-reported respiratory symptoms (14-16). This study estimated doctor-diagnosed asthma, selfreported asthma, and asthma risk in the study population in order to compare the three commonly used measures of asthma. Asthma risk was determined using the asthma diagnostic checklist developed by the American College of Allergy, Asthma, and Immunology (17). The checklist consisted of a series of 13 yes/no questions used by the ACAAI in a national screening program to identify potential asthmatics. The checklist has also been used as a screening tool in numerous clinical settings including the University of Michigan Health Services (18). If the respondent answered yes to four or more of the checklist questions, the individual was considered at some risk for asthma. At risk respondents who reported wheezing symptoms with or without a cold, or wheezing that caused breathing difficulty were classified as selfreported asthmatics. Doctor-diagnosed asthma was defined as lifetime history of asthma diagnosis by a physician.

Asthma severity was determined by scoring asthma symptoms from a validated questionnaire developed by Robins et al. (19) using a scoring technique from questionnaire by Joffres et al. (20). Respondents identified as being at risk for asthma, as well as self-reported and doctor-diagnosed asthmatics were asked a series of questions about symptoms including cough, wheeze, and chest tightness. For each reported symptom, the respondent was asked to rate the frequency and intensity of the symptom during the past 12 months. For frequency, there were four levels of response ranging from rarely to all the time, which were assigned values from one for rarely to four for all of the time. For intensity, there were three levels of response ranging from low to high, which were assigned numerical values from one for low to three for high. The severity for each individual symptom was calculated as the product of the frequency and intensity for that symptom. A summary score of total asthma severity for each respondent was calculated by summing the severity score for each individual symptom. Total severity had a potential minimum of zero if the respondent experienced no symptoms of asthma, and a potential maximum score of 96 if the respondent experienced all the symptoms with a high intensity all the time.

Respondents identified with asthma were presented with a list of common asthma triggers and asked to indicate the factors that commonly exacerbated their symptoms. The list included exercise, cosmetic aerosols or cleaning products, colds or flu, cold air, weather, laughing or crying hard, dust, pets, air pollution, pollen/trees or fresh cut grass, mold or mildew, smoke, cockroaches, and certain foods. Respondents with asthma were also asked to indicate if there was a season during which they experienced exacerbated asthma symptoms, given the following choices: fall (September, October, November), winter (December, January, February), spring (March, April, May), or summer (June, July, August). 


\section{Statistical Analysis}

Survey data was entered and stored in an Epi Info 2000 database prior to analysis (CDC Division of Public Health Surveillance and Informatics, Atlanta, GA). Statistical analyses were performed using SAS 8.0 (SAS Institute, Cary, NC). Asthma prevalence, overall asthma severity, and symptom severity were used as dependent variables. Environmental and demographic characteristics of the study population were used as independent variables. Associations between independent and dependent variables were evaluated using logistic regression. The relationships between independent variables and dependent frequency, intensity, and severity outcomes were assessed using general linear regression. Basic descriptive statistics were generated using univariate and frequency analysis. Because the sample was limited to Arab Americans, no weighting was used in the analysis. All tests were considered statistically significant at alpha $<0.05$.

\section{RESULTS}

\section{Demographic Characteristics}

Respondents consisted of first and secondgeneration immigrants from the Middle East; over $90 \%$ had their roots in Yemen, Iraq, and Lebanon. About $32 \%$ of the respondents spoke Arabic only, while $1.2 \%$ spoke English only. The remaining $67 \%$ were bilingual. Approximately $45 \%$ of study population had lived in the United States for 10 years or more, $4 \%$ had lived in the United States for less than 1 year, and 5.5\% were born in the United States. The population was relatively stable-respondents reported living in their neighborhoods for an average of 7.2 years (Table II).

Female respondents comprised $58 \%$ of the study population (Table II). Interviews were conducted more frequently during weekdays than at night or on weekends. This may have led to an overrepresentation of housewives, because male wage earners would be less likely to be at home during weekdays. Respondents' ages ranged from under 20 $(4.5 \%)$ to 70 or older $(6 \%)$ with the median age range being $31-41$ years (Table II). About $77 \%$ of the respondents were married, $85 \%$ had a regular family doctor, and $75 \%$ had health care coverage for themselves (Table II). Health care coverage rates were considerably higher than previously reported estimates (21); the reason for this disparity is unclear.

Number of people in the households ranged from 1 to 13 people, with the mean being 4.6 persons (Table II). The total number of children in the household averaged 1.9 (Table II). Approximately $40 \%$ of the population completed primary school or less, $12 \%$ of the respondents had no formal education, $19 \%$ continued their education beyond high school, and only $4 \%$ completed a college degree. About $29 \%$ of the respondents had formal employment when the survey was conducted. The fact that the interviews were mostly conducted during weekdays could have led to an over-representation of unemployment within the population, as people with day jobs would have been away from home during survey times. Only $4.4 \%$ reported being employed as professionals at any time, past or present. Of the unemployed adult population, 59\% had never worked for pay. This estimate may reflect the high percentage of housewives included in the study, but most likely reflected the high percentage of self-employment in the community. Among the 209 respondents willing to disclose their household income, $11 \%$ had no

Table II. Demographic Characteristics of the Study Population

\begin{tabular}{lccc}
\hline & Mean (median) & Range & Percent \\
\hline Gender & & & \\
$\quad$ Female & & & 58.0 \\
$\quad$ Male & 4.6 & $1-13$ & 42.0 \\
Total household members & 1.9 & $0-10$ & \\
Total children in household & 7.2 & $1-32$ & \\
Years in neighborhood & $(31-41$ years $)$ & Under $18-$ over 70 & \\
Age & & & 85.0 \\
Regular family doctor & & & 75.0 \\
Healthcare coverage & & & 29.0 \\
Currently employed & $(\$ 6,000-11,999)$ & No income-over $\$ 50,000$ & \\
Income & & & \\
\hline
\end{tabular}


income, $7.2 \%$ had a yearly total household income of $\$ 50,000$ or more, and the median income was $\$ 6,000$ 11,999 (Table II).

\section{Asthma Prevalence, Severity, and Triggers}

Almost $30 \%$ of the adult study population reported respiratory impairment in the form of having trouble breathing, coughing with strenuous chores or walking, or exacerbated breathing difficulty due to tobacco smoke, fumes, or strong odors (Table III). Approximately $22 \%$ reported exacerbated breathing difficulty due to dust, pollen, or pets (Table III).

By contrast, about half of the asthmatics in the study population reported: wheezing with exercise, cough with exercise, sleep disturbed by cough, wheezing, chest tightness, or shortness of breath, and difficulty breathing due to wheezing attack (Table IV). The most commonly reported symptoms were wheezing without a cold, and tightness or heavy feeling in the chest, which were experienced by $63 \%$ of the asthmatic population (Table IV). Average symptom scores ranged from 2.1 to 2.8 on a scale of 1 (rarely) to 4 (most of the time) for frequency, 1.72.1 on a scale of 1 (low) to 3 (high) intensity, and 3.6-5.9 on a scale of 1-12 for severity (Table IV). These measures suggest that Arab American asthmatics in Detroit coughed and wheezed a lot of the time of living in an area with degraded environmental.
About $12 \%$ of the adult study population was identified as being at high risk for asthma by the ALA checklist (Table III), while $7.5 \%$ was classified as self-reported asthmatics (Table III). Another $8.2 \%$ of the study population had been diagnosed with asthma by a physician (Table III). At the time of data collection for this study, approximately $9.7 \%$ of the US population and $10.3 \%$ of the population in Michigan had been diagnosed with asthma during their lifetime (22). Those estimates have increased to 11.8 and $12.8 \%$, respectively (23). The reported prevalence of doctor diagnosed asthma in the Detroit metropolitan area is approximately $13.5 \%$ (24). Although the prevalence of asthma among some ethnic groups including African Americans and Hispanics is generally higher than the prevalence in the general population $(23,25)$, the prevalence among Arab Americans in this study population was lower than the national, statewide, and metro Detroit population averages.

The prevalence of total asthma (doctordiagnosed + self-reported) was $10 \%$ in Oak Park, $12 \%$ in Hamtramck, $17 \%$ in Dearborn, and $20 \%$ in Detroit's 7 Mile area. Little epidemiological data is available for asthma prevalence in the Middle East. WHO reports asthma prevalence ranging from $2.3-10 \%$ among countries in the region (26).

As noted previously, aggregate measures of asthma severity were derived by summing individual symptom severity scores for all asthmatics. The range

Table III. Asthma Measures and Their Relationships With Environmental Risk Index (ERI)

\begin{tabular}{lrrc}
\hline & & \multicolumn{2}{c}{ Correlation } \\
& & \multicolumn{2}{c}{ with ERI } \\
\cline { 2 - 5 } & Percent & OR value \\
\hline & & & \\
& & NS & NS \\
Doctor-diagnosed asthma & 7.5 & 1.2 & 0.0005 \\
Self-reported asthma & 12.0 & 1.2 & 0.0005 \\
Asthma risk & 15.7 & 1.1 & 0.011 \\
Total asthma & 6.8 & 1.2 & 0.0009 \\
Trouble breathing/coughing with simple chores/walking & 26.0 & 1.1 & 0.032 \\
Trouble breathing/coughing with strenuous chores/walking & 13.0 & $\mathrm{NS}$ & $\mathrm{NS}$ \\
Avoids exercise/sports due to breathing trouble/coughing & 9.1 & 1.1 & 0.013 \\
Unable to sleep without coughing attacks/shortness of breath & 12.0 & 1.1 & 0.0047 \\
Sometimes can't catch a good, deep breath & 9.5 & 1.2 & $<0.0001$ \\
Occasional wheezing & 11.0 & 1.1 & 0.038 \\
Occasional chest tightness & 22.0 & $\mathrm{NS}$ & $\mathrm{NS}$ \\
Dust/pollen/pets exacerbate breathing difficulty & 13.0 & 1.2 & 0.0003 \\
Cold weather exacerbates breathing difficulty & 28.0 & 1.1 & 0.0025 \\
Tobacco smoke/fumes/strong odors exacerbate breathing difficulty & 10.0 & $\mathrm{NS}$ & $\mathrm{NS}$ \\
Colds often move to chest & 5.7 & 1.1 & 0.019 \\
1+ visits to ER in past year due to breathing problems & 2.9 & 1.2 & 0.0055 \\
1+ overnight hospitalizations in past year due to breathing problems & &
\end{tabular}


Table IV. Symptom Frequency, Intensity, and Severity Among Asthmatics in the Study Population

\begin{tabular}{lcccc}
\hline & Prevalence (\%) & Frequency (mean) $^{a}$ & ${\text { Intensity }(\text { mean })^{b}}^{\left.\text {Severity }^{(m e a n}\right)^{c}}$ \\
\hline Persistent cough & 37 & 2.4 & 1.9 & 4.6 \\
Wheezing with a cold & 63 & 2.5 & 1.9 & 4.9 \\
Wheezing without a cold & 27 & 2.1 & 1.8 & 4.1 \\
Difficulty breathing due to wheezing attack & 53 & 2.4 & 1.7 & 4.3 \\
Wheezing with exercise & 45 & 2.8 & 2.1 & 5.9 \\
Cough with exercise & 48 & 2.4 & 1.9 & 4.9 \\
Tightness or heavy feeling in chest & 63 & 2.1 & 1.9 & 3.6 \\
Sleep disturbed by cough, wheezing, & 49 & & 4.3 \\
$\quad$ chest tightness, or shortness of breath & & & \\
\hline
\end{tabular}

absolute range: $1-4$.

${ }^{b}$ Absolute range: $1-3$.

${ }^{c}$ Absolute range: $1-12$.

in severity scores was from 2 to 85 with a mean value of 19. The estimated distribution of asthma severity scores is skewed to the left (Fig. 1). This distribution pattern provides us a quantitative scale for categorizing the severity of asthma in the study population into mild (score of 1-19), moderate (score of 20-40) and severe (score > 40). On the basis of this categorization scheme, $50 \%$ of the asthma cases would be mild, while $0.83 \%$ would be severe. According to this measure, asthma seventy appeared to be lower among Arab Americans in Oak Park (average score $=12$ ) compared with those residing in Detroit's seven Mile area (average score $=$ 18) Hamtramck (average score $=23$ ), and Dearborn (average score $=19)$. The severity scores are con- sistent with the fact that Oak Park is primarily a residential community whereas the Arab American communities in the other three areas live close to major industrial complexes. The distribution patterns for measures of frequency and intensity (graphs not presented in this paper) are similar to that of asthma severity.

Among the asthmatic individuals in the study population, it would appear that exposure to typical risk factors (such as pets, pollen, mold and mildew, or roaches) did not generally precipitate asthma attacks (Table V). On the other hand, more than $70 \%$ of the at-risk individuals reported that sprays or strong smells including perfume, cologne, and cleaning supplies, colds or flu, change in weather, air pollution,

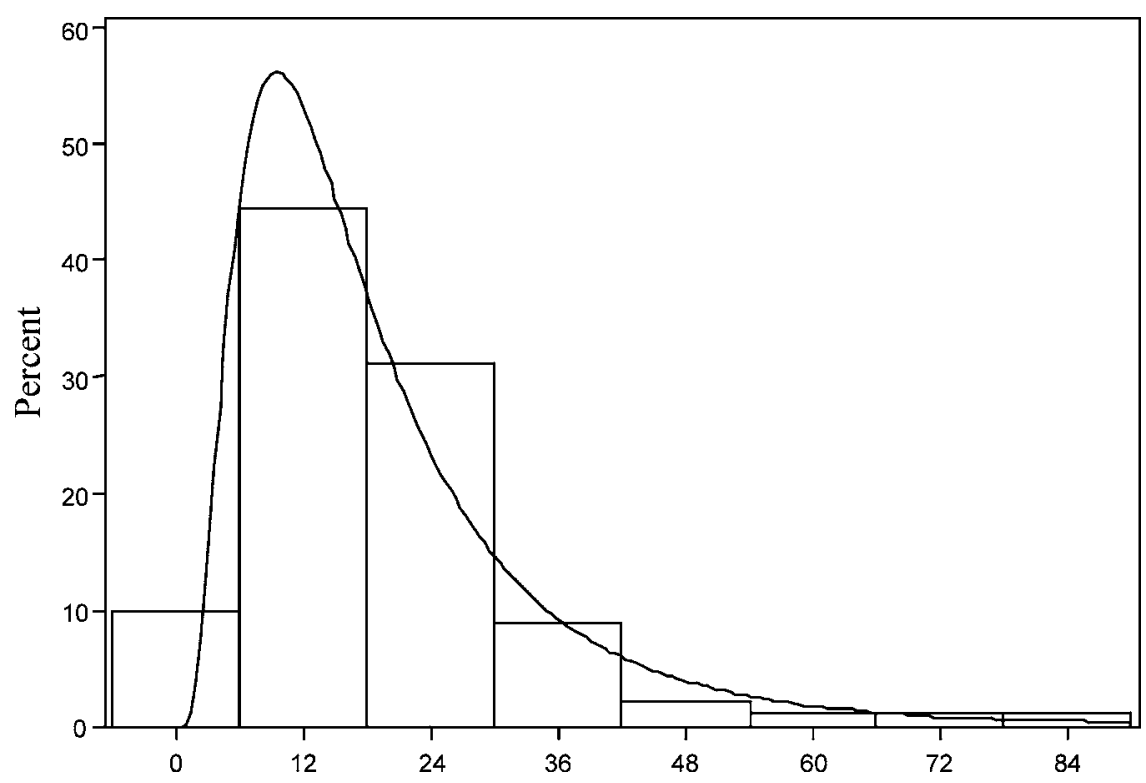

Fig. 1. Asthma severity score. 
Table V. Asthma Triggers in the Community

\begin{tabular}{lc}
\hline & Percent \\
\hline $\begin{array}{l}\text { Being active, like running, playing, swimming, } \\
\quad \text { or exercising }\end{array}$ & 61 \\
$\begin{array}{l}\text { Sprays or strong smells, like colognes, perfumes, } \\
\quad \text { or cleaning supplies }\end{array}$ & 76 \\
Colds or flu & 77 \\
Cold air & 49 \\
Change in weather & 70 \\
Laughing or crying hard & 17 \\
Dust & 81 \\
Pets & 17 \\
Air pollution & 79 \\
Pollen, trees, fresh cut grass & 53 \\
Mold and mildew & 45 \\
Smoke & 75 \\
Cockroaches & 13 \\
Certain foods & 14 \\
\hline
\end{tabular}

and tobacco smoked brought on wheezing, chest tightness, coughing, or shortness of breath (Table V). Self-reported symptom exacerbation among Arab Americans in metro Detroit peaked in the winter, and displayed a corresponding trough in the summer (Fig. 2). Peak exacerbation during the winter may be related to the large proportion of asthmatics in the population who reported that colds and flu triggered their asthma symptoms or increase exposure to indoor bioaerosols during the heating season (Table V). Seasonal asthma trends in the literature are typically based on: hospital admissions and mortality (27-33). Seasonal distribution based on self-reported symptoms in this study appears to be consistent with patterns of peak hospitalization and mortality for (older) adults in the literature $(29,30)$, although the peak does occur later than the reported fall peak in many studies $(27,28,31)$.

\section{Environmental Factors}

According to the ranking scheme used in this study, the likely minimum score for the ERI is -6 and the maximum likely score is +40 (see Table I). The observed ERI scores have a skewed distribution (Fig. 3) and ranged in value from 1 to 17 , with the mean being 6.0. The association between ERI and asthma prevalence can be used to subdivide the ERI into Low to Moderate Risk (score of 0-9) and Elevated Risk (score of 10 or higher). On the basis of this categorization scheme, $89 \%$ of the households in this study would be classified as low to moderate risk, while $11 \%$ would be classified as elevated risk.

ERI was significantly associated with selfreported asthma, total (doctor diagnosed + selfreported) asthma, and a number of common asthma symptoms (Table III, VII). There was also a significant difference between the average ERI score for Dearborn (4.9) and those for Oak Park (7.5), Detroit Seven Mile (7.9) and Hamtramck (7.3), possibly due to the educational and intervention efforts by ACCESS, which is located in Dearborn ( $\mathrm{p}$ value $<$ 0.0001).

Among the individual variables included in the ERI we found that weather-stripped windows, water leaks into the house, cockroach problems, difficulty getting the landlord to make repairs,



Fig. 2. Seasonal distribution of asthma. 


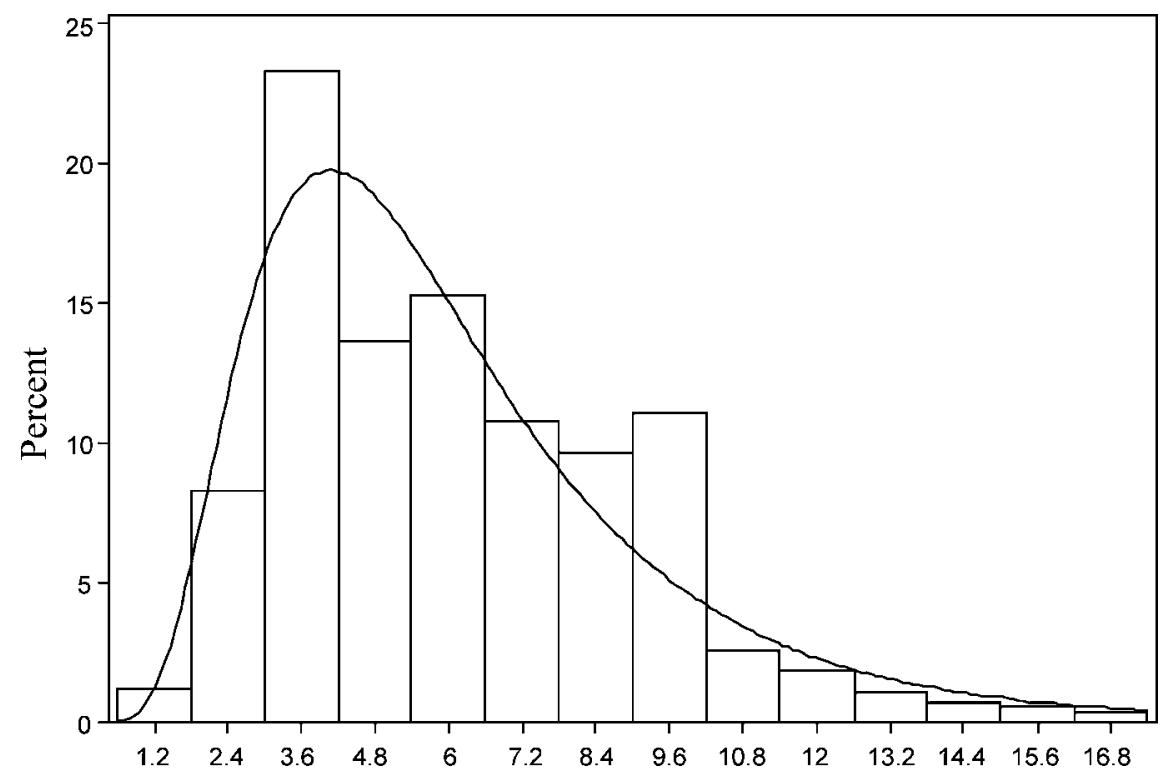

Fig. 3. Environmental risk index.

and low satisfaction with home quality were positively associated with self-reported and total asthma prevalence (Table VI). Variables that were negatively associated with asthma included: double-

Table VI. Demographic and Environmental Predictors of Total Asthma Prevalence $^{a}$

\begin{tabular}{lcll}
\hline & $P$ value & OR & $95 \%$ CI \\
\hline $\begin{array}{l}\text { Demographic } \\
\text { Gender }\end{array}$ & NS & & \\
Age & 0.041 & 1.1 & {$[1.0,1.3]$} \\
Degree of Acculturation & 0.0053 & & \\
Less than 1 year in U.S. & 0.055 & 1.7 & {$[0.69,4.4]$} \\
1-10 years in U.S. & 0.0020 & 0.51 & {$[0.32,0.82]$} \\
Regular family doctor & 0.066 & 2.0 & {$[0.95,4.4]$} \\
Education & 0.011 & 0.87 & {$[0.78,0.97]$} \\
Current employment & 0.051 & & \\
Income & $\mathrm{NS}$ & & \\
City & $\mathrm{NS}$ & & \\
Environmental & & & \\
Environ risk index (ERI) & 0.011 & 1.1 & {$[1.0,1.8]$} \\
Repairs not done & 0.024 & 1.6 & {$[1.1,2.3]$} \\
Quality of home & 0.0080 & 1.6 & {$[1.1,2.2]$} \\
Central air conditioning & $\mathrm{NS}$ & & \\
Daytime indoor temp & $\mathrm{NS}$ & & \\
Water leaks in family room & 0.0098 & 3.6 & {$[1.4,9.6]$} \\
Any water leaks & 0.033 & 2.0 & {$[1.1,3.7]$} \\
Cockroaches & 0.011 & 2.1 & {$[1.2,3.8]$} \\
Weather stripped windows & $<0.0001$ & 2.6 & {$[1.6,4.2]$} \\
Weather stripped doors & $\mathrm{NS}$ & & \\
Double paned windows & 0.0012 & 0.46 & {$[0.28,0.73]$} \\
Storm windows & 0.052 & 0.64 & {$[0.41,1.0]$} \\
\hline NS not signicant. & & & \\
\hline
\end{tabular}

${ }^{a} \mathrm{NS}=$ not significant. paned windows (doctor-diagnosed, self-reported and overall asthma prevalence), storm windows (self-reported and overall asthma prevalence), and home ownership (self-reported asthma) (Table VI). Several factors which have been correlated with asthma in the literature such as: type of home, age of home, construction material, basement, heating sources, type of furnace, air filter on furnace (HEPA or otherwise), pet ownership and care, pesticide use, and garage (35-40) were not significant predictors of asthma prevalence in this study, while others such as central air conditioning and home ownership were only significant predictors of self-reported asthma. Environmental risk factors were weak predictors of asthma frequency, intensity, and severity in this study. With a few exceptions, environmental risk factors were not significantly associated with asthma frequency, intensity, and severity (Table VII). That said, home quality was positively associated with frequency, intensity, and severity; and water leaks were positively associated with asthma intensity (Table VII).

\section{Demographic Factors}

Age, acculturation and SES surrogates such as education and current employment status were predictive of asthma prevalence, but not frequency, intensity, or severity (Table VI). Birth in the United 
Table VII. Demographic and Environmental Predictors of Asthma Severity

\begin{tabular}{lcrc}
\hline & $P$ value & Beta & $95 \%$ CI \\
\hline Born outside US & 0.0007 & -20.0 & {$[-31.0,-8.4]$} \\
Language (Reference = English only) & & \\
Arabic only & $<0.0001$ & -65.0 & {$[-90.0,-40.0]$} \\
Arabic better than English & $<0.0001$ & -68.0 & {$[-93.0,-43.0]$} \\
Both equally & $<0.0001$ & -66.0 & {$[-92.0,-41.0]$} \\
English better than Arabic & $<0.0001$ & -61.0 & {$[-87.0,-34.0]$} \\
Previous employment type: & 0.053 & & \\
Quality of home & 0.019 & 5.1 & {$[0.86,9.3]$} \\
\hline
\end{tabular}

States and fluency in English were positively associated with asthma severity (Table VI). Gender and country of origin were not significantly associated with asthma prevalence or severity in this study.

\section{DISCUSSION}

Current asthma research generally follows the traditional paradigm in which risk factors are considered individually as predictors of disease. The risk factor approach can elucidate simple relationships between adverse exposures and development of disease, and has in fact led to such insights in asthma research, but offers little analysis or explanation for overlapping, mutually interdependent relationships. Furthermore, little attention is paid to interpretation of the underlying risk factors. This failure to interpret the collateral variables (or their proxies) obscures the true relationship between environmental exposures and disease outcomes. This study tries to use the aggregated environmental risk factors (ERI) to examine the environmental-SES-cultural interrelationships in the development and expression of asthma in the Arab American communities (Table VIII).

\section{Environmental Factors}

The relationships between asthma prevalence and individual household risk factors have been the focus of most previous studies (41). Most of the relationships between asthma and ERI variables in this study were consistent with the existing literature. However, some previously identified risk factors were not significantly associated with asthma in this study. This may be due to specific cultural and socioeconomic characteristics of the study population. For example, the lack of association between pets and asthma is most likely due to the low frequency of pet ownership, particularly cat and dog ownership, among Arab Americans in this study.

The role of weatherproofing in asthma etiology was ambiguous in this study. Weather stripped windows were positively associated with asthma, while storm windows and double paned windows were both negatively associated with asthma. We would expect weatherproofing to influence asthma by decreasing ventilation - thereby increasing indoor air pollution-or by increasing indoor temperature, either of which would explain the positive association between asthma and weather-stripped windows. The apparent inconsistencies with respect to storm windows and double paned windows imply that these types of weatherproofing may be related to SES, and as such, may be surrogates for other variables such as home quality, which have a protective effect with respect to asthma.

A goal of this study is to derive a surrogate measure of an aggregate environmental risk (an environmental risk index) for a given household. ERI was a significant predictor of self-reported asthma, total asthma, and asthma symptoms. The strong association between ERI and asthma in this study suggests that with further refinement, the ERI can become a suitable household surrogate for predicting asthma risk. The strong association between environmental exposures and asthma prevalence rather than severity in this study suggests that environmental exposures may influence asthma development whereas the severity is more related to disease management.

Table VIII. Overview of Asthma Risk Factors

\begin{tabular}{|c|c|c|}
\hline Risk Factor Domains & Underlying risk factors & Surrogates for risk \\
\hline Lifestyle & $\begin{array}{l}\text { Diet, exercise, patterns of healthcare utilization and } \\
\text { environmental exposures, }\end{array}$ & Culture/ethnicity, gender, SES \\
\hline Environment & $\begin{array}{l}\text { Adverse conditions ins the indoor and outdoor } \\
\text { environment }\end{array}$ & $\begin{array}{l}\text { ERI, neighborhood, zip code, city, SES, } \\
\text { population density }\end{array}$ \\
\hline Genetics & $\begin{array}{l}\text { Predisposition toward atopy, physiological lung changes, } \\
\text { or immune responses involved in asthma etiology }\end{array}$ & $\begin{array}{l}\text { Parental history of atopic disorders including } \\
\text { asthma, eczema, hay fever, etc. }\end{array}$ \\
\hline
\end{tabular}




\section{Demographic Factors}

Surrogates for SES such as education, and employment status were predictive of asthma prevalence, but not frequency, intensity, or severity (Table VI). Although numerous studies have associated SES with asthma (42-45), the underlying mechanism responsible for this association remains unclear. Low SES can act as proxy for substandard housing or bad neighborhood effects, both of which have been positively associated with self-reported asthma and exacerbation of asthma symptoms (46). Low SES has been correlated with increased risk of delivering low birth weight babies, who are subsequently at higher risk of developing asthma $(7,42)$. SES effects have also been attributed to lack of access to medical care treatment (42-44). Lester et al. (47) found higher rates of asthma hospitalization predicted by low family income, unemployment, and low educational level independent of race or ethnicity, which suggests that low SES is correlated either with greater severity or differences in health care utilization. The lack of correlation between SES and asthma severity and intensity observed in the present study may be related to the fact that $85 \%$ of the respondents reported having a regular family doctor while $75 \%$ claimed to have health insurance to facilitate asthma management.

Separating the effects of SES from the effects of ethnicity can also be difficult in the United States, where race and SES are highly correlated (48). Neighborhood effects may further diminish differences in SES between minorities living in close proximity. For instance, Miller (49) reported that SES was more highly correlated with asthma among nonminority group members. In this study, the focus on Arab Americans living in proximal neighborhoods reduces potential confounding due to ethnicity and neighborhood effects; while the fact that country of origin was not found to be a significant predictor of asthma prevalence, frequency, intensity, or severity may further reduce the concern about the potential role of ethnicity as a confounder. The results of this study are thus consistent with the absence of significant correlation between SES and asthma reported in several national surveys $(50,51)$, which suggests that SES may only act as a surrogate for asthma risk factors in specific segments of the population.

There was no significant association between asthma prevalence or severity and gender in the study population. Gender differences in asthma morbidity and prevalence have been noted inconsistently in the literature. In some studies male gender was considered a risk factor (42); in others females were at higher risk (52); while other studies found no significant association between gender and asthma (50). One logical explanation for the conflicting reports is the differential risk to which the males and females are exposed in terms of risk behaviors (such as cooking by women), smoking and on the job; intrinsic biological differences may have little bearing on the gender differences $(43,53,54)$. Asthma prevalence was positively associated with age among adults in this study, suggesting that age acts as a proxy for asthma risk factors such as long-term exposure to environmental pollutants $(55,56)$, or physiological changes implicated in asthma etiology. Because age was closely associated with self-reported rather than doctor-diagnosed asthma, it is unlikely that the association is due to an increase in cumulative probability of diagnosis.

In contrast with findings among Latino communities in the United Sates, there was no significant association between country of origin and asthma in this study. Lara et al. (57) reported a correlation between country of origin and asthma morbidity, while Ledogar et al. (58) found an association between country of origin and asthma prevalence among Latinos residing in shared neighborhoods, suggesting that cultural background can play a significant role in asthma etiology. The disparity between these findings and those of the current study suggest either that country of origin is not an appropriate surrogate for cultural differences among Arab Americans in this community, or that those differences do not play a role in asthma etiology.

Birth in the United States and fluency in English were positively associated with asthma severity (Table VII). However, length of residence in the neighborhood was not significantly associated with asthma prevalence or severity, as would be expected if increased exposure to high pollution levels in metro Detroit were responsible for the positive association between asthma severity and residence in the United States. A more likely explanation is that these factors are related to asthma management. In light of the potential importance of early childhood exposures in asthma development (2,59-63), it is also possible that respondents born in the United States suffer more severe asthma due to early exposure to "Western" risk factors.

The relationship between acculturation and asthma prevalence in this community suggests an interesting trend. Arab Americans with a moderate 
degree of acculturation (those residing in the United States from 1-10 years) were at lower risk for asthma compared with both new immigrants (residing in the United States for less than a year) and fully acculturated Arab Americans (residing in the United States for more than 10 years or born in the United States). For new immigrants, translocation may result in increased psychosocial stress, which can increase the likelihood of disease; while new immigrant status may result in lower SES, substandard housing, and lack of access to adequate medical care. For wellacculturated individuals, risk factors associated with western lifestyle such as high fat diet and sedentary behavior may lead to an increased risk of asthma (64). The individuals who have resided in the United States for 1-10 years may be at lower risk because, compared to the new immigrants, they have better housing and better access to health care but have not yet begun to experience the negative consequences associated with western lifestyle.

Demographic predictors of severity and prevalence did not overlap in this study. Traditional surrogates for socioeconomic status such as education and employment status were predictive of asthma prevalence, but not asthma severity, frequency, or intensity; while English fluency and birth in the United States were strong predictors of asthma severity, frequency, and intensity, but not prevalence. These results suggest that SES variables may be more reflective of environmental exposures in communities involved in this study. In contrast, demographic variables such as English fluency and birth in the United States may impact severity by influencing health care access and utilization behavior related to asthma management. While acculturation may reflect a number of factors ranging from SES and environmental exposure to lifestyle and mental health status, the observed associations in this report suggest: 1) that it acts primarily as a proxy for risk factors associated with asthma development, and 2) that western lifestyle factors influence asthma development rather than asthma management or exacerbation.

\section{Asthma Burden Among Arab Americans in Detroit, Michigan}

The prevalence of asthma among Arab American adults in this study was similar to the national and state averages. However, it is interesting to note that while the asthma prevalence in metro Detroit is higher than the national and state averages $(22,23,25)$; the prevalence among Arab
Americans appears to be considerably lower than the average prevalence in metro Detroit (24), and higher than the prevalence of asthma among Arabs in the Middle East (26). These relationships are consistent with the acculturation trend discussed earlier, suggesting that the burden of asthma among Arab Americans will increase as immigrants become better acculturated, unless we make a greater effort to understand the overlapping "Western" risk factors involved in asthma etiology.

Although every effort was made to reduce sampling bias and increase the power of this study, there are potential limitations which must be addressed: 1) in the sampling design, the selection of households from predominantly Arab American neighborhoods may have led to an overrepresentation of Arab Americans with a low degree of acculturation, or low SES, which could result in bias if the reported relationships between risk factors and asthma as well as reported asthma prevalence were extrapolated to the larger Arab American population in metro Detroit; 2) while a sample size of 600 is adequate for estimating prevalence, and rudimentary regressions, small response strata may have impacted some of our findings, either by elevating chance events to statistical significance, or by obscuring potentially meaningful relationships as noted with pet ownership. This concern warrants further investigation of the trends noted in this study, particularly with respect to the impacts of acculturation, English fluency, and birth in the United States. Although our results suggest that ERI and the proposed measure of asthma severity have the potential to be useful assessment tools, this study does not attempt to formally validate these instruments. Despite its potential limitations, this study suggests several interesting relationships between asthma risk factors, introduces useful tools for assessing environmental risk, and characterizes disease burden in an understudied, marginalized population.

\section{ACKNOWLEDGMENTS}

The project was funded by an National Institute of Environmental Health Science (NIEHS) grant under the Environmental Justice Program.

\section{REFERENCES}

1. Meliker JR, Nriagu JO, Hammad AS, Savoie KL, Jamil H, Devries JM: Spatial clustering of emergency department visits by asthmatic children in an urban area: Southwest Detroit, Michigan. Ambul Child Health 2001; 7:297-312 
2. Beasley R, Crane J, Lai CK, Pearce N: Prevalence and etiology of asthma. J Allergy Clin Immunol 2000; 105 (2, Pt 2):S466-S472

3. Tobias A, Soriano JB, Chinn S, Anto JM, Sunyer J, Burney P: European Community Respiratory Health Survey. Symptoms of asthma, bronchial responsiveness and atopy in immigrants and emigrants in Europe. Eur Respir J. 2001; 18(3):459465

4. Powell CV, Nolan TM, Carlin JB, Bennett CM, Johnson PD: Respiratory symptoms and duration of residence in immigrant teenagers living in Melbourne, Australia. Arch Dis Childhood 1999; 81(2):159-162

5. Strachan DP, Anderson HR, Limb ES, O'Neil A, Wells N: A national survey of asthma prevalence, severity, and treatment in Great Briatin. Arch Dis. Childhood 1994; 70:174-178

6. Leung RC, Carlin JB, Burdon JG, Czarny D: Asthma, allergy and atopy in Asian immigrants in Melbourne. Med J Austr 1994; 61(7):418-425

7. Eggleston PA: Environmental causes of asthma in inner city children. The National Cooperative Inner City Asthma Study. Clin Rev Allergy Immunol 2000; 18(3):311-324

8. Nriagu JO, Robins $T$, Gary L, Liggans G, Davila R, Supuwood K, Harvey C, Jinabhai CC, Naido R: Prevalence of asthma and respiratory symptoms in south-central Durban, South Africa. Eur J Epidemiol 1999; 15:747-755

9. Sarafino EP, Goldfedder J. 1995. Genetic factors in the presence, severity, and triggers of asthma. Arch Dis Childhood 1995; 73(2):112-116

10. Sarafino EP: Connections among parent and child atopic illnesses. Pediatr Allergy Immunol 2000; 11:80-86

11. Parker EA, Israel BA, Williams M, Brakefield-Caldwell W, Lewis TC, Robins T, Ramirez E, Rowe Z, Keeler G: Community action against asthma: Examining the partnership process of a community-based participatory research project. J Gen Int Med 2003; 18(7):558-567

12. O'Fallon LR, Dearry A: Community-based participatory research as a tool to advance environmental health sciences. Environ Health Perspect 2002; 110(Suppl 2):155-159

13. Johnson M: Risk factors for asthma among Arab American immigrants in the Metro Detroit area. Doctoral Thesis. 2005

14. Keeler GJ, Dvonch T, Yip FY, Parker EA, Isreal BA, Marsik FJ, Morishita M, Barres JA, Robins TG, Brakefield-Caldwell W, Sam M: Assessment of personal and community-level exposures to particulate matter among children with asthma in Detroit, Michigan, as part of Community Action Against Asthma (CAAA). Environ Health Perspect 2002; 110(Suppl 2):173-181

15. Clark NM, Brown RW, Parker E, Robins TG, Remick DG Jr, Philbert MA, Keeler GJ, Israel BA: Childhood asthma. Environ Health Perspect 1999; 107(Suppl 3):421-429

16. Clark NM, Brown R, Joseph CL, Anderson EW, Liu M, Valerio M, Gong M: Issues in identifying asthma and estimating prevalence in an urban school population. J Clin Epidemiol. 2002; 55(9):870-881

17. Joseph CL, Foxman B, Leickly FE, Peterson E, Ownby D: Prevalence of possible undiagnosed asthma and associated morbidity among urban schoolchildren. J Pediatr 1996; 129(5):735-742

18. American College of Allergy, Asthma and Immunology (ACAAI): Nationwide Asthma Screening Program. 2003. Available at http://allergy.mcg.edu/lifeQuality/nasp.html

19. University of Michigan Health Services: 2004. Available at http://www.med.umich.edu/wheas/test.htm

20. Robins TG, Parker EA, Israel BA, Brown RW, Lewis TC, CAAA Steering Committee: Use of a screening questionnaire to estimate prevalence of diagnosed and undiagnosed asthma among minority children in Detroit. Presentation at American Thoracic Society Presentation: San Francisco, CA; 2001
21. Joffres M, Williams T, Sabo B, Fox RA: Environmental sensitivities: Prevalence of major symptoms in a referral center: The Nova Scotia Environmental Sensitivities Research Center study. Environ Health Perspect 2001; 109:161-165

22. Savoie K, Nriagu J: Air Pollution Health Risk Assessment of the Arab American Community in Dearborn, Michigan. Report to US EPA, Region 5, Air and Radiation Division; 1999

23. Mannino DM, Homa DM, Akinbami LJ, Moorman JE, Gwynn C, Redd SC: Surveillance for asthma-United States, 1980-1999. Morb Mortal Wkly Rep. Surveillance Summaries 2002; 51(1):1-13

24. Rhodes L, Bailey CM, Moorman JE: Surveillance for asthmaUnited States, 1980-1999. Morb Mortal Wkly Rep. Surveillance Summaries 2004; 53(07):145-148

25. CDC National Center for Chronic Disease Prevention and Health Promotion: The Selected Metropolitan/Micropolitan Area Risk Trends (SMART); 2002. Project: http://apps. nccd.cdc.gov/brfss-smart/MMSARiskChart.asp?yr $=2002 \&$ MMSA $=26 \&$ cat $=$ AS\&qkey $=290 \&$ grp $=0$

26. Rhodes L, Moorman JE, Redd SC, Mannino DM: Selfreported asthma prevalence and control among adultsUnited States, 2001. Morb Mortal Wkly Rep. Surveillance Summaries 2003; 52(17):381-384

27. WHO Regional Office for the Eastern Mediterranean: Non-communicable disease s-regional situation report; 2004 Available at http://www.emro.who.int/ncd/NCD-Regional Situation-Asthma.htm

28. Silverman RA, Stevenson L, Hastings HM: Age-related seasonal patterns of emergency department visits for acute asthma in an urban environment. Ann Emergency Med 2003; 42(4):577-586

29. Crighton EJ, Mamdani MM, Upshur RE: A population based time series analysis of asthma hospitalisations in Ontario, Canada: 1988 to 2000. BMC Health Serv Res 2001; 1(1):7

30. Kimbell-Dunn M, Pearce N, Beasley R: Seasonal variation in asthma hospitalizations and death rates in New Zealand. Respirology 2000; 5(3):241-246

31. Nichols T, Hansell A, Strachan D: The contribution of 'holiday deaths' to seasonal variations in asthma mortality in England and Wales. Clin Exp Allergy1999; 29(10):14151417

32. Dales RE, Schweitzer I, Toogood JH, Drouin M, Yang W, Dolovich J, Boulet J: Respiratory infections and the autumn increase in asthma morbidity. Eur Respir J 1996; 9(1):7277

33. Kimes D, Levine E, Timmins S, Weiss SR, Bollinger ME, Blaisdell C: Temporal dynamics of emergency department and hospital admissions of pediatric asthmatics. Environ Res 2004; 94(1):7-17

34. Gergen PJ, Mitchell H, Lynn H: Understanding the seasonal pattern of childhood asthma: Results from the National Cooperative Inner-City Asthma Study (NCICAS). J Pediatr 2002; 141(5):631-6

35. Bardana EJ, Jr: Indoor pollution and its impact on respiratory health. Ann Allergy Asthma Immunol 2001; 87(6, Suppl 3):33-40

36. Lanphear BP, Kahn RS, Berger O, Auinger P, Bortnick SM, Nahhas RW: Contribution of residential exposures to asthma in us children and adolescents. Pediatrics 2001; 107(6):E98

37. Lanphear BP, Aligne CA, Auinger P, Weitzman M, Byrd RS: Residential exposures associated with asthma in US children. Pediatrics 2001; 107(3):505-511

38. Maier WC, Arrighi HM, Morray B, Llewellyn C, Redding GJ: Indoor risk factors for asthma and wheezing among Seattle school children. Environ Health Perspect 1997; 105(2):208214

39. McConnell R, Berhane K, Gilliland F, Islam T, Gauderman WJ, London SJ, Avol E, Rappaport EB, Margolis HG, Peters 
JM: Indoor risk factors for asthma in a prospective study of adolescents. Epidemiology 2002; 13(3):288-295

40. Somerville M, Mackenzie I, Owen P, Miles D: Housing and health: Does installing heating in their homes improve the health of children with asthma? Public Health 2000; 114(6):434-439

41. Johnston SL, Holgate ST. Asthma: Critical Issues. London: Blackwell; 2002

42. Lemanske RF, Jr: Issues in understanding pediatric asthma: Epidemiology and genetics. J Allergy Clinical Immunol. 2002; 109(6, Suppl):S521-S524

43. Hjern A, Haglund B, Bremberg S, Ringback-Weitoft G: Social adversity, migration and hospital admissions for childhood asthma in Sweden. Acta Paediatrica 1999; 88(10):11071112

44. Aber JL, Bennett NG, Conley DC, Li J: The effects of poverty on child health and development. Ann Rev Public Health 1997; 18:463-483

45. Schwartz J, Gold D, Dockery DW, Weiss ST, Speizer FE: Predictors of asthma and persistent wheeze in a national sample of children in the United States. Am Rev Respir Dis 1990; 142:555-562

46. Krieger J, Higgins DL: Housing and health: Time again for public health action. Am J Public Health 2002; 92(5):758-768

47. Lester MR, Schneider LC: Atopic diseases and upper respiratory infections. Curr Opin Pediatrics 2000; 12(5):511519

48. Grant EN, Alp H, Weiss KB: The challenge of inner-city asthma. Curr Opin Pulmon Med1999; 5(1):27-34

49. Miller JE: The effects of race/ethnicity and income on early childhood asthma prevalence and health care use. Am J Public Health 2000; 90(3):428-430

50. Rodriguez MA, Winkleby MA, Ahn D, Sundquist J, Kraemer HC: Identification of population subgroups of children and adolescents with high asthma prevalence: Findings from the third natinal health ad nutrition examination survey. Arch Pediatr Adolesc Med. 2002; 156(3)269275

51. Newachek PW, Halfon N: Prevalence, impact, and trends in childhood disability due to asthma. Arch Pediatr Adolesc Med 2000; 154:287-293
52. Woodruff PG, Prescott SL, Holt PG, Fahy JV: Antenatal factors in the development of atopy and asthma. In: Johnson SL, Holgate ST, ed. London: Blackwell; pp.116-137; 2002

53. Jarvis D, Chinn S, Luczynska C, Burney P: Association of respiratory symptoms and lung function in young adults with use of domestic gas appliances. Lancet 1996; 347(8999):426-431

54. Peters JM, Avol E, Navidi W, London SJ, Gauderman WJ, Lurmann F, Linn WS, Margolis H, Rappaport E, Gong H, Thomas DC: A study of twelve Southern California communities with differing levels and types of air pollution. I. Prevalence of respiratory morbidity. Am J Respir Crit Care Med 1999; 159(3):760-767

55. Malo JL, Chan-Yeung M: Occupational asthma. J. Allergy Clin Immun 2001; 108(3):317-328

56. McDonnell WF, Abbey DE, Nishino N, Lebowitz MD: Longterm ambient ozone concentration and the incidence of asthma in nonsmoking adults: The AHSMOG Study. Environ Res 1999; 80(2, Pt 1):110-121

57. Lara M, Morgenstern H, Duan N, Brook RH: Elevated asthma morbidity in Puerto Rican children: A review of possible risk and prognostic factors. Western J Med 1999; 170(2):75-84

58. Ledogar RJ, Penchaszadeh A, Garden CCI, Acosta LG: Asthma and Latino cultures: Different prevalence reported among groups sharing the same environment. Am J Public Health 2000; 90(6):929-935

59. Johnson CC, Ownby DR, Zoratti EM, Alford SH, Williams LK, Joseph CL: Environmental epidemiology of pediatric asthma and allergy. Epidemiol Rev 2002; 24(2):154-175

60. Douwes J, Pearce N: Asthma and the westernization 'package.' Int J Epidemiol 2002; 31(6):1098-1102

61. Gern JE, Lemanske RF, Jr, Busse WW: Early life origins of asthma. J Clin Invest 1999; 104(7):837-843

62. Martinez FD: Maturation of immune responses at the beginning of asthma. J Allergy Clin Immunol 1999; 103(3, Pt 1):355-361

63. Martinez FD: Gene by environment interactions in the development of asthma. Clin Exp Allergy 1998; (28, Suppl 5):21-25

64. Spector SL, Surette ME: Diet and asthma: Has the role of dietary lipids been overlooked in the management of asthma? Ann Allergy Asthma Immunol 2003; 90(4):371-377 